\title{
miR-200/ZEB axis regulates sensitivity to nintedanib in non-small cell lung cancer cells
}

\author{
NOBUHIKO NISHIJIMA, MASAHIRO SEIKE, CHIE SOENO, MIKA CHIBA, AKIHIKO MIYANAGA, \\ RINTARO NORO, TEPPEI SUGANO, MASARU MATSUMOTO, KAORU KUBOTA and AKIHIKO GEMMA
}

\author{
Department of Pulmonary Medicine and Oncology, Graduate School of Medicine, \\ Nippon Medical School, Bunkyo-ku, Tokyo 113-8603, Japan
}

Received October 16, 2015; Accepted November 22, 2015

DOI: $10.3892 /$ ijo.2016.3331

\begin{abstract}
Nintedanib (BIBF1120) is a multi-targeted angiokinase inhibitor and has been evaluated in idiopathic pulmonary fibrosis and advanced non-small cell lung cancer (NSCLC) patients in clinical studies. In the present study, we evaluated the antitumor effects of nintedanib in 16 NSCLC cell lines and tried to identify microRNA (miRNA) associated with sensitivity to nintedanib. No correlations between FGFR, PDGFR and VEGFR family activation and sensitivity to nintedanib were found. The difference in miRNA expression profiles between 5 nintedanib-sensitive and 5 nintedanib-resistant cell lines was evaluated by miRNA array and quantitative RT-PCR analysis (qRT-PCR). Expression of miR-200b, miR-200a and miR-141 belonging to the miR-200 family which contributes to epithelial-mesenchymal transition (EMT), was significantly lower in 5 nintedanib-resistant than in 5 nintedanib-sensitive cell lines. We examined the protein expression of EMT markers in these 10 NSCLC cell lines. E-cadherin expression was lower, and vimentin and ZEB1 expression were higher in 5 nintedanib-resistant cell lines. PC-1 was the most sensitive of the NSCLC cell lines to nintedanib. We established nintedanib-resistant PC-1 cells (PC-1R) by the stepwise method. PC-1R cells also showed decreased expression of miR-200b, miR-141 and miR-429 and increased expression of ZEB1 and ZEB2. We confirmed that induction of miR-200b or miR-141 enhanced sensitivity to nintedanib in nintedanib-resistant A549 and PC1-R cells. In addition, we evaluated the response to gefitinib in combination with nintedanib after TGF- $\beta 1$ exposure of A549 cells. Nintedanib was able to reverse TGF- $\beta 1$-induced EMT and resistance to gefitinib caused by $\mathrm{miR}-200 \mathrm{~b}$ and $\mathrm{miR}-141$ upregulation and ZEB1 downregulation. These results
\end{abstract}

Correspondence to: Dr Masahiro Seike, Department of Pulmonary Medicine and Oncology, Graduate School of Medicine, Nippon Medical School, 1-1-5, Sendagi, Bunkyo-ku, Tokyo, 113-8603, Japan E-mail: mseike@nms.ac.jp

Key words: miR-200, nintedanib, lung cancer, EGFR-TKI, drug resistance suggested that the miR-200/ZEB axis might be predictive biomarkers for sensitivity to nintedanib in NSCLC cells. Furthermore, nintedanib combined with gefitinib might be a novel therapeutic strategy for NSCLC cells with EMT phenotype and resistance to gefitinib.

\section{Introduction}

Lung cancer is still the leading cause of cancer-related death throughout the world (1). In recent genome studies, oncogenic driver mutations including EGFR gene mutation and ALK fusion gene have been discovered in non-small cell lung cancer (NSCLC) patients (2-4). First-line treatments with EGFR-tyrosine kinase inhibitors (TKIs) including gefitinib, erlotinib and afatinib and ALK-inhibitor crizotinib showed higher response rate and superior progression-free survival (PFS) compared with standard cytotoxic chemotherapy and are recognized as the standard therapies for the treatment of advanced NSCLC with driver mutations (5-8). Based on these findings, another small-molecular-targeted drug has recently been developed and its efficacy and safety have been evaluated in NSCLC patients.

Nintedanib (BIBF1120) is a potent, oral angiokinase inhibitor that targets VEGFR-1-3, PDGFR- $\alpha$ and $\beta$, and FGFR-1-3 signaling (9). Nintedanib has been evaluated for the treatment of idiopathic pulmonary fibrosis (IPF) $(10,11)$. Recent phase III studies demonstrated that nintedanib reduced the decline in forced vital capacity, resulting in decreased frequency of acute exacerbations in patients with IPF with tolerable adverse events $(10,11)$. The US Food and Drug Administration (FDA) approved nintedanib as a new drug for IPF in 2014 based on these trials. IPF treatment has entered a new era by the development of nintedanib. Nintedanib has also been evaluated for the treatment of various solid tumors including advanced NSCLC (12). The LUME-Lung-1 phase III trial showed that nintedanib in combination with docetaxel is an effective second-line therapy for advanced NSCLC patients, especially for lung adenocarcinoma patients (12). This was the first evidence for a molecular targeted agent showing an effect in combination therapy with cytotoxic agents after failure of platinum doublet chemotherapy in NSCLC patients. Therefore, identification of predictive biomarkers for the response to nintedanib and 
patient selection based on the biomarker may have a clinical benefit for NSCLC patients treated with nintedanib.

MicroRNAs (miRNAs) are single-stranded, 18-24-nucleotide, non-coding molecules that post-transcriptionally modulate gene expression through binding to 3'UTRs of target mRNAs. miRNAs, which usually induce gene silencing, can function as either tumor suppressors or oncogenes $(13,14)$. Previous studies revealed that miRNAs were diagnostic, prognostic and therapeutic biomarkers in lung cancer $(15,16)$. Our previous study demonstrated that inhibition of miR-21 and miR-134/487b/655 cluster expression could be used as a therapeutic strategy in connection with EGFR-tyrosine kinase inhibitor (EGFR-TKI) treatment $(17,18)$. These findings suggest that miRNAs may be promising predictive biomarkers and therapeutic targets in NSCLC.

In the present study, we examined the miRNA profile in order to clarify which miRNA is associated with sensitivity to nintedanib using 16 NSCLC cell lines. We demonstrate that miR-200b and miR-141 associated with epithelialmesenchymal transition (EMT) are predictive biomarkers and therapeutic targets of nintedanib in NSCLC cells. Furthermore, we found that nintedanib inhibited EMT and reversed the resistance to EGFR-TKI with TGF- $\beta$-induced EMT through miR-200 family induction in NSCLC cells.

\section{Materials and methods}

Cell lines. We used the following 16 NSCLC cell lines in the present study: A549, PC-3, PC-9, PC-14, NCI-HCC827, NCI-H1650, NCI-H1975, LC-2/ad and RERF-LC-KJ adenocarcinoma (AC) cell lines and PC-1, PC-10, LK-2, SQ5, QG56, EBC-1 and LC-1/sq squamous-cell carcinoma (SQ) cell lines. A549, NCI-H1650 and NCI-H1975 were purchased from the American Type Culture Collection (ATCC; Manassas, VA, USA); RERF-LC-KJ, SQ5, LC-2/ad and LC-1/sq were obtained from Riken Cell Bank (Ibaraki, Japan); PC-1, PC-3, PC-9, PC-10 and PC-14 were obtained from ImmunoBiological Laboratories (Gunma, Japan); and EBC-1, LK-2, and QG56 were purchased from Health Science Research Resources Bank (Osaka, Japan). Lung cancer cell lines were maintained in RPMI-1640 medium (Gibco, Carlsbad, CA, USA) supplemented with $10 \%$ fetal bovine serum (FBS). These cell lines were obtained from 2008 to 2009, amplified and frozen, and one aliquot of each was thawed for this project. All cells were routinely screened for the absence of mycoplasma.

Drugs and growth-inhibition assay. Nintedanib and gefitinib were purchased from Selleck Chemicals (Houston, TX, USA). Growth inhibition was assessed by the MTS assay to examine the effect of nintedanib on the 16 NSCLC cell lines. Cell suspensions (5,000 cells/well) were seeded into 96 -well plates and increasing concentrations of nintedanib $(0,0.01 .0 .1,1.0$ and $10 \mu \mathrm{M})$ were added. After incubation at $37^{\circ} \mathrm{C}$ for $72 \mathrm{~h}$, MTS was added to each well and incubated at $37^{\circ} \mathrm{C}$ for $2 \mathrm{~h}$, after which absorbance was measured using a microplate reader with a test wavelength of $450 \mathrm{~nm}$. The $\mathrm{IC}_{50}$ value was defined as the concentration needed for $50 \%$ reduction of the growth by treatment with nintedanib by SigmaPlot12 (Hulinks, Inc., Tokyo, Japan). A549 and PC-1R cells (5,000 cells/well) were seeded into 96-well plates for $24 \mathrm{~h}$, and then incubated in the various concentrations of nintedanib at $37^{\circ} \mathrm{C}$ for $72 \mathrm{~h}$ after exposure to $\mathrm{miR}-200 \mathrm{mimic}$, miR-141 mimic or miR-mimic-control (Cont-mimic) at a final concentration of $40 \mathrm{nM}$ for $24 \mathrm{~h}$.

RNA extraction and miRNA microarray analysis. Total RNA was extracted from four lines with TRIzol reagent (Invitrogen, Carlsbad, CA, USA) as previously described (19,20). Total RNA (5 $\mu \mathrm{g})$ was employed for hybridization on miRNA microarray chips containing 667 probes with the TaqMan ${ }^{\circledR}$ Array Human MicroRNA A + B Cards Set v2.0 (Life Technologies, Carlsbad, CA, USA) on a 7900 Real-Time PCR System (Applied Biosystems, Foster City, CA, USA). Processed slides were scanned with a PerkinElmer ScanArray XL5K scanner. Experimental data were analyzed by DataAssist ${ }^{\mathrm{TM}}$ software (Life Technologies) using RNU44 and RNU48 as endogenous controls. $\mathrm{Ct}$ values were provided from all miRNAs represented on the cards and fold changes in expression were calculated using the delta $\mathrm{Ct}(\Delta \Delta \mathrm{Ct})$ method. Expression levels of MammU6 on the array card were defined as positive controls for the purpose of $\Delta \Delta \mathrm{Ct}$ calculation.

Real-time quantitative reverse transcription-PCR. The expression levels of miR-200 family members were measured by quantitative reverse transcription-PCR (qRT-PCR) using TaqMan ${ }^{\circledR}$ MicroRNA assay system (Applied Biosystems). The RNU66 expression level was determined by qRT-PCR as an internal control (Applied Biosystems). miRNA expression was quantified and reported as $2^{-\triangle \Delta C T}$ value (21).

Western blot analysis and receptor tyrosine kinase phospholylation array. Cells were dissolved in buffer containing $50 \mathrm{mM}$ Tris- $\mathrm{HCl}, \mathrm{pH} 7.6,150 \mathrm{mM} \mathrm{NaCl}, 0.1 \%$ sodium dodecyl sulfate, $1 \%$ Nonidet P-40 and $0.5 \%$ sodium-deoxycholate. The lysates were cooled with ice for $30 \mathrm{~min}$, and then centrifuged at $13,000 \times \mathrm{g}$ for $30 \mathrm{~min}$. Proteins $(10 \mu \mathrm{g})$ in the collected supernatant were separated by SDS-PAGE on $12 \%$ gels and then transferred to nitrocellulose membranes. The membrane, after a block with 5\% skim milk, was incubated with antibodies to E-cadherin, vimentin, ZEB1, $\beta$-actin (Cell Signaling Technology, Beverley, MA, USA) and ZEB2 (Sigma-Aldrich, St. Louis, MO, USA). Each protein was detected by immunoblotting with ECL-Plus reagents (GE Healthcare Bio-Science Corp., Piscataway, NJ, USA). We also performed human receptor tyrosine kinase (RTK) phosphorylation antibody arrays including 71 antibodies (RayBiotech, Inc., Norcross, GA, USA) as previously described (22).

Oligonucleotide transfection. miR-200b and miR-141 mimics, and their negative control (Cont-mimic), were synthesized by Ambion (Austin, TX, USA). All mimics were treated with Lipofectamine 2000 transfection reagent $24 \mathrm{~h}$ after seeding, as per the manufacturer's instructions (Life Technologies). The mimic complexes were transfected into cells at a final concentration of $40 \mathrm{nM}$. The transfection medium was replaced $6 \mathrm{~h}$ later and cells were then incubated at $37^{\circ} \mathrm{C}$ for $48 \mathrm{~h}$. TGF- $\beta 1$ was purchased from R\&D Systems, Inc. (Minneapolis, MN, USA). Cells were exposed to $5 \mathrm{ng} / \mathrm{ml}$ TGF- $\beta 1$ for the indicated period of time. 
Table I. Sensitivity to nintedanib of 16 NSCLC cell lines and their genetic status.

\begin{tabular}{|c|c|c|c|c|c|c|}
\hline Cell lines & Pathology & Nintedanib $\mathrm{IC}_{50}$ & EGFR mut & ALK fusion & KRAS mut & MET amp \\
\hline PC-1 & SQ & 1.0 & - & - & - & - \\
\hline QG56 & SQ & 1.9 & - & - & - & - \\
\hline LK-2 & SQ & 2.5 & - & - & - & - \\
\hline EBC-1 & SQ & 3.2 & - & - & - & + \\
\hline PC-9 & $\mathrm{AC}$ & 3.2 & Ex19 del & - & - & - \\
\hline NCI-HCC827 & $\mathrm{AC}$ & 3.9 & Ex19 del & - & - & - \\
\hline NCI-H1975 & $\mathrm{AC}$ & 5.9 & Ex19 del, T790M & - & - & - \\
\hline RERF-LC-KJ & $\mathrm{AC}$ & 7.3 & - & - & - & - \\
\hline PC-10 & SQ & 7.7 & - & - & + & - \\
\hline PC-14 & $\mathrm{AC}$ & 7.7 & - & - & - & - \\
\hline NCI-H1650 & $\mathrm{AC}$ & 20 & L858R & - & - & - \\
\hline A549 & $\mathrm{AC}$ & 25 & - & - & + & - \\
\hline SQ5 & SQ & 27 & - & - & - & - \\
\hline PC-3 & $\mathrm{AC}$ & 71 & - & - & - & - \\
\hline $\mathrm{LC}-1 / \mathrm{sq}$ & SQ & 78 & - & - & - & - \\
\hline LC-2/ad & $\mathrm{AC}$ & $>100$ & - & - & + & - \\
\hline
\end{tabular}

SQ, squamous cell carcinoma; AC, adenocarcinoma; Ex19 del, Exon 19 deletion; T790M, Exon 20 T790M mutation; L858R, Exon 21 L858R mutation; mut, mutation; amp, amplification.

Statistical analysis. Data were expressed as the mean (SD) of three independent experiments and evaluated with the Student's t-test. $\mathrm{P}<0.05$ were defined as statistically significant.

\section{Results}

Effect of nintedanib on the growth of 16 NSCLC cell lines. Growth-inhibitory effects of nintedanib on 16 NSCLC cell lines were assessed by MTS assay. Gene status of EGFR mutation, ALK rearrangement, KRAS mutation and MET amplification were evaluated by LCI Medience Corp. (Tokyo, Japan). Table I shows the sensitivity to nintedanib of 16 NSCLC cell lines and their genetic status. Nintedanib had $\mathrm{IC}_{50}$ values of $>1 \mu \mathrm{M}$, which is above the pharmacologically achievable concentration in mammals $(0.45 \mu \mathrm{M})$, in the 16 NSCLC cell lines (9). However, PC-1 cells without genetic alterations were relatively sensitive to nintedanib $(1.0 \mu \mathrm{M})$. There were no correlations between nintedanib $\mathrm{IC}_{50}$ and pathological type or genetic status.

Correlation between FGFR/PDGFR/VEGFR expression and drug sensitivity. Based on the $\mathrm{IC}_{50}$, we placed NSCLC cell lines into two groups, namely, nintedanib-sensitive and nintedanibresistant cell lines. Five cell lines (PC-1, QG56, LK-2, EBC-1 and $\mathrm{PC}-9)$ were sensitive $\left(\mathrm{IC}_{50}\right.$ of $\left.\leq 3.2 \mu \mathrm{M}\right)$, and 5 other cell lines were resistant to nintedanib (A549, SQ5, PC-3, LC-1/sq and LC-2/ad) $\left(\mathrm{IC}_{50}\right.$ of $\left.>25 \mu \mathrm{M}\right)$ (Table I). First, RTK phosphorylation profiles including FGFR, PDGFR and VEGFR family kinases were investigated in the 5 nintedanib-sensitive and 5 nintedanib-resistant cell lines to clarify whether the kinases were associated with sensitivity to nintedanib. The relationship between RTKs phosphorylation and nintedanib sensitivity is shown in Fig. 1A. Phosphorylation of ROR1 and
SRMS was significantly increased in nintedanib-resistant cells. However, the phosphorylation status of FGFR1/2, PDGFR $\alpha / \beta$ and VEGFR2/3 showed no significant differences between the sensitive and resistant cell lines (Fig. 1A). This result suggested that activation of targets of nintedanib, FGFR, PDGFR and VEGFR kinases, does not affect the sensitivity of NSCLC cells to nintedanib.

Correlation between miRNA expression and drug sensitivity. In order to identify miRNAs that contribute to the sensitivity to nintedanib, we compared miRNA expression profiles between the 5 nintedanib-sensitive and 5 nintedanib-resistant cell lines by miRNA array. The expression of 7 miRNAs was significantly altered in the nintedanib-resistant cell group compared to the nintedanib-sensitive cell group (fold changes of $>2.0$ or $<0.5$ ) (Fig. 1B). Among them, expression of three miR-200 family members, miR-200b, miR-200a and miR-141, were significantly downregulated in the nintedanib-resistant cell lines (Fig. 1B). The miR-200 family contains five miRNAs: miR-200a/200b/429 on chromosome 1 and miR-200c/141 on chromosome 12. The levels of miR-200c and miR-429 expression tended to be decreased in the nintedanib-resistant cell group (Fig. 1B). The expression levels of miR-200 family members were validated by qRT-PCR (Fig. 2A). The expression levels of miR-200 family members were higher in the 5 nintedanib-sensitive cell lines than in the resistant cell lines except for LC-1/sq cells (Fig. 2A). The miR-200 family members have been described as a main suppressor of EMT by targeting ZEB1 and ZEB2 (23). Therefore, we evaluated the protein expression of EMT markers in the 10 NSCLC cell lines. Epithelial marker E-cadherin expression was lower, and mesenchymal marker vimentin expression was higher in the 5 nintedanib-resistant cell lines (Fig. 2B). Expression of ZEB1 
A

PC-1 QG56 LK-2 EBC-1 PC-9 A549 SQ5 PC-3 LC-1/sq LC-2/ad change Pvalue

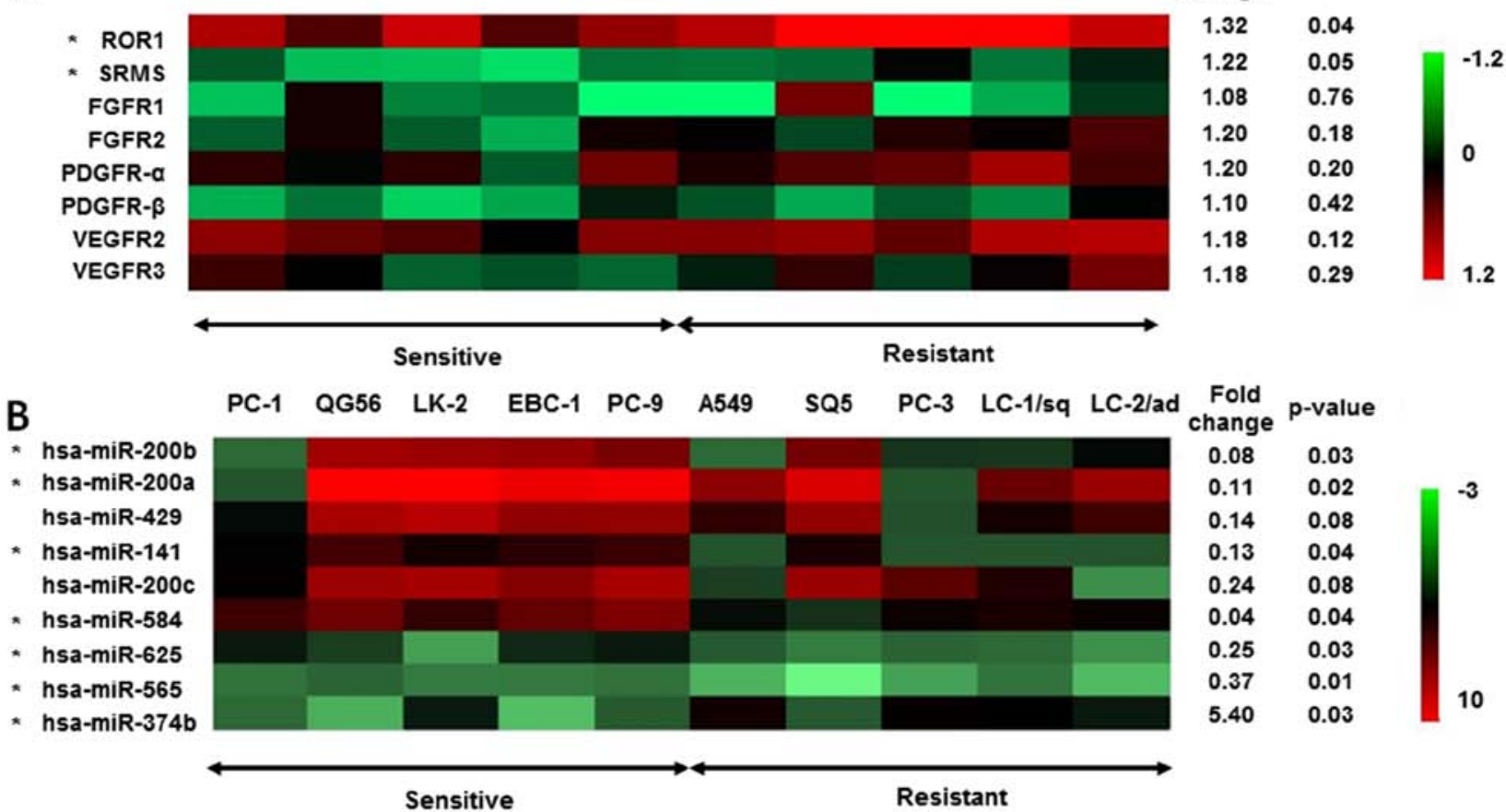

Figure 1. Unique RTKs and miRNA correlated with the resistance to nintedanib. Heatmap of differential levels of RTKs phosphorylation (A) and miRNAs (B) between 5 nintedanib-sensitive and 5 nintedanib-resistant NSCLC cell lines. An immortalized tracheal cell line (BET2A) was used as a normal control cells. The $\log 2$ ratio [ $\log 2$ (NSCLC cells/BET2A cells)] was calculated for each array. Fold change means the relative ratio of the resistant cells against the sensitive cells. ${ }^{*} \mathrm{P}<0.05$.
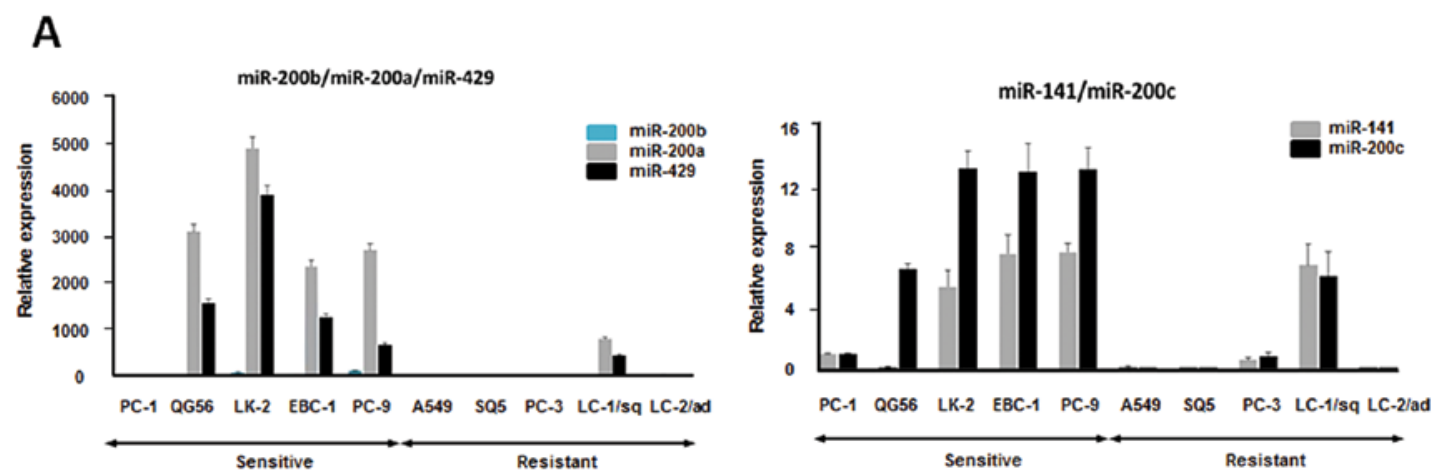

B

PC-1 QG56 LK-2 EBC-1 PC-9 A549 SQ5 PC-3 LC-1/sq LC-2/ad

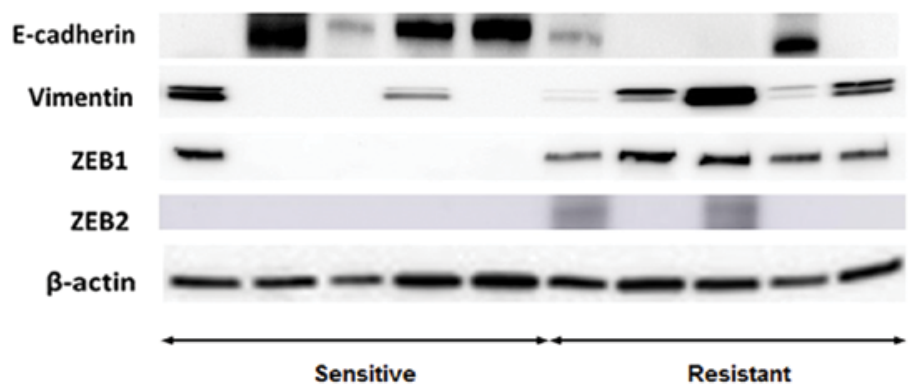

Figure 2. Differences in miR-200b and miR-141 expression between nintedanib-sensitive and nintedanib-resistant NSCLC cells. (A) miR-200b/200a/429 and miR-141/200c expression profiles between 5 nintedanib-sensitive and 5 nintedanib-resistant NSCLC cell lines were assessed by qRT-PCR analysis. Relative expression was calculated based on the expression level in PC-1. (B) Protein expression of EMT markers including E-cadherin, vimentin, ZEB1 and ZEB2 in 10 NSCLC cell lines was assessed by western blotting.

which is well known as a direct target of the miR-200 family was also increased in the 5 nintedanib-resistant cell lines
(Fig. 2B). ZEB2 expression was found in 2 of the 5 nintedanibresistant cell lines (Fig. 2B). These results suggested that the 
A

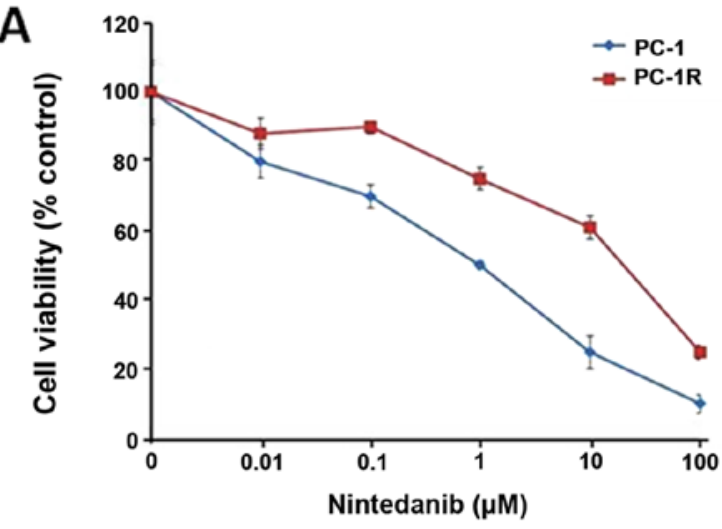

B

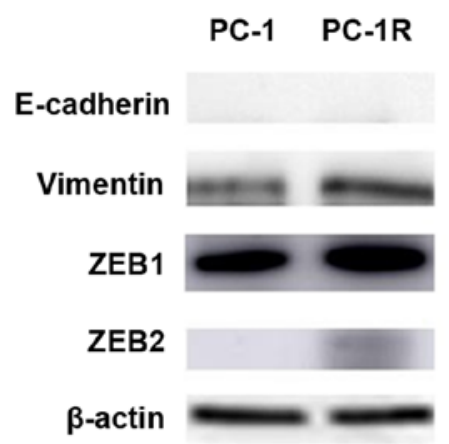

C miR-200b miR-200a $\operatorname{miR}-429$

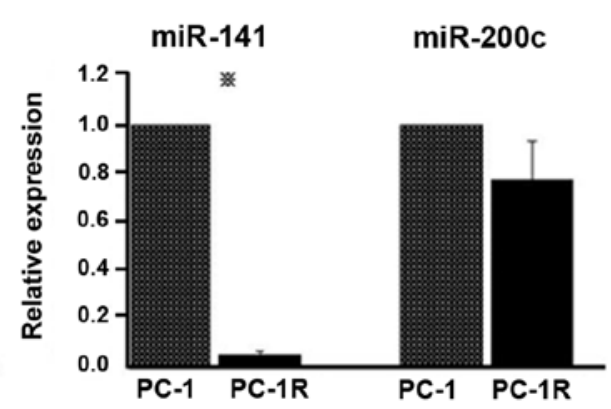

Figure 3. Establishment of nintedanib-resistant PC1-R cells and evaluation of miR-200 family expression and miR-141 expression and EMT markers in PC1-R cells. (A) MTS assays with nintedanib in PC-1 and PC-1R cells. Data are expressed as the mean \pm SD from 3 independent experiments. (B) Increased vimentin, ZEB1 and ZEB2 expression in PC1-R cells on western blotting. (C) miR-200b/200a/429 and miR-141/200c expression levels were decreased in PC-1R cells on qRT-PCR analysis. Data are expressed as mean \pm SD from 3 independent experiments. ${ }^{*} \mathrm{P}<0.05$.

mesenchymal phenotype may be involved in the resistance to nintedanib in NSCLC cells.

Establishment of nintedanib-resistant PCl cells and evaluation of miR-200 family expression and EMT markers. To further clarify the mechanism of resistance to nintedanib, we tried to establish nintedanib-resistant PC-1 cells by continuous exposure to increasing concentrations of nintedanib in a stepwise manner. After two months, we established nintedanib-resistant PC-1 cell lines; PC-1R survived upon incubation with $25 \mu \mathrm{M}$ nintedanib and we used these PC1-R cells in further investigations (Fig. 3A). The expression levels of vimentin, ZEB1 and ZEB2 were increased in PC1-R cells compared to PC-1 cells (Fig. 3B). Furthermore, miR-200b, miR-141 and miR-429 expression levels were significantly decreased in PC1-R cells compared to PC-1 cells (Fig. 3C). Based on these results, we focused on the miR-200 family and ZEB, especially miR-200b and miR-141 and their target ZEB1, as candidate miRNAs and their target associated with sensitivity to nintedanib in NSCLC cells.

miR-200 family regulated EMT and nintedanib sensitivity in NSCLC cells. To further examine whether the miR-200 family regulates the response to nintedanib, nintedanibresistant A549 cells were transfected with a miR-200b or miR-141 mimic and control mimic for $72 \mathrm{~h}$. We confirmed that miR-200b and miR-141 were overexpressed after the miR-200b or miR-141 mimic was incubated with A549 cells (Fig. 4A). ZEB1 expression was diminished resulting in increased E-cadherin and decreased vimentin expres- sion in A549 cells treated with miR-200b mimic (Fig. 4B). Overexpression of miR-141 decreased ZEB1 and increased E-cadherin expression (Fig. 4B). Next, we investigated the effect of overexpression of the two miRNAs on the sensitivity of A549 cells to nintedanib. Induction of miR-200b or miR-141 mimics enhanced the sensitivity of A549 cells to nintedanib (Fig. 4C). Furthermore, miR-200b or miR-141 overexpression reversed the resistance to nintedanib of PC1-R cells (Fig. 4D). These results suggested that suppression of the miR-200 family is involved in the resistance to nintedanib in NSCLC cells.

Nintedanib restored drug resistance to gefitinib by activating the miR-200 family. EMT has been recognized as one of the mechanisms of resistance to EGFR-TKI in NSCLC with EGFR mutation $(24,25)$. In addition, a recent study demonstrated that nintedanib induced mesenchymal-epithelial transition (MET) in A549 lung cancer cells (26). Therefore, we evaluated whether nintedanib overcomes EMT and the resistance to the EGFR-TKI gefitinib in NSCLC cells. A549 cells were exposed to TGF- $\beta 1$ and then treated with nintedanib for $72 \mathrm{~h}$. Fig. 5A shows that the conversion from epithelial phenotype to mesenchymal phenotype induced by TGF- $\beta 1$ was more inhibited in A549 cells treated with nintedanib (Fig. 5A). We observed that the increases in vimentin and ZEB1 expression and decrease in E-cadherin expression activated by TGF- $\beta 1$ were more reduced in A549 cells treated with nintedanib (Fig. 5B). Furthermore, decreased miR-200b and miR-141 expression caused by TGF- $\beta 1$ was restored after treatment with nintedanib (Fig. 5C). We also measured the 

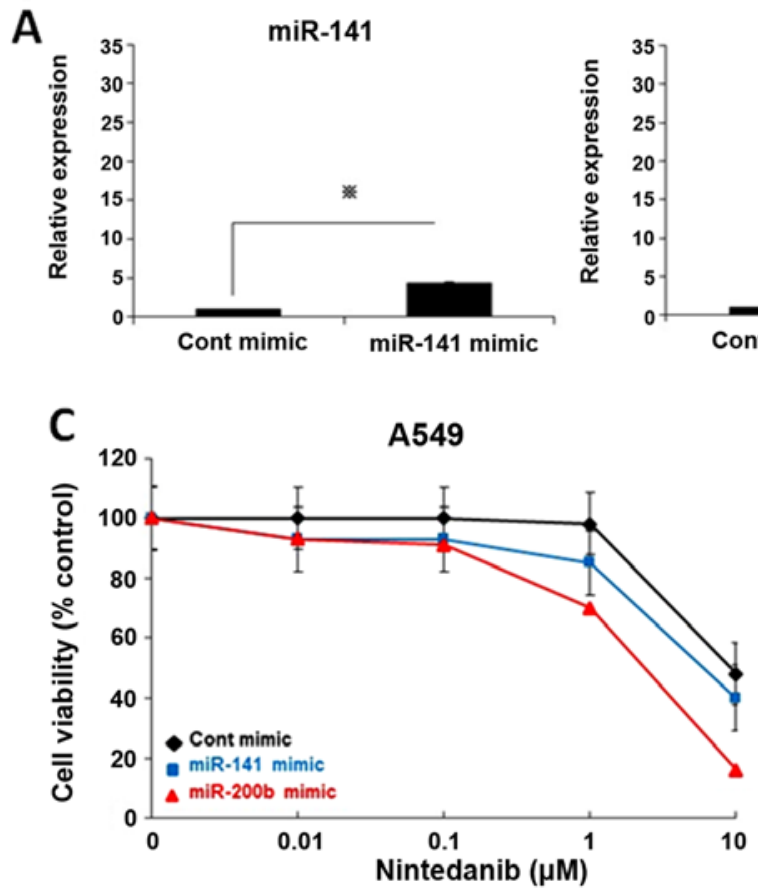
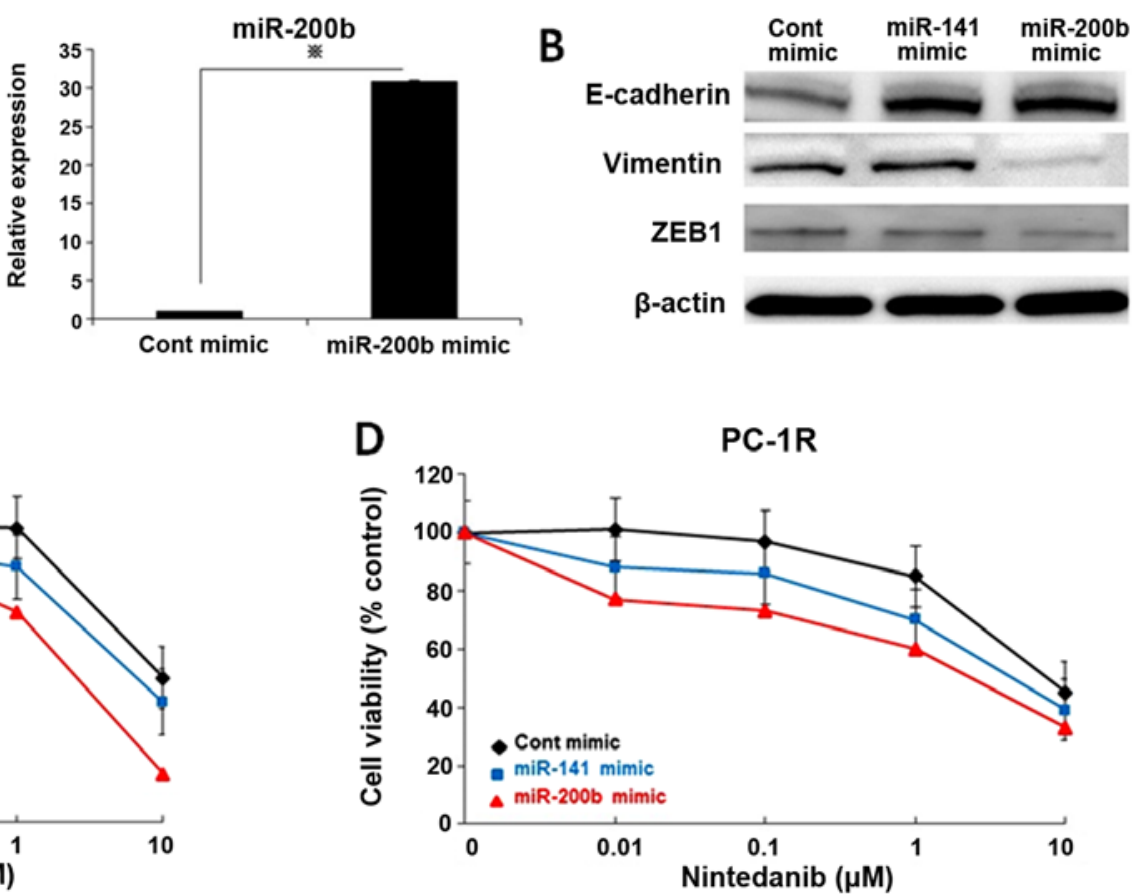

Figure 4. miR-200 family regulated EMT and nintedanib sensitivity in A549 and PC-1R cells. (A) The levels of miR-200b and miR-141 expression were elevated in A549 cells after transfection of miR-200b or miR-141 mimic for $72 \mathrm{~h}$ by qRT-PCR analysis. Cont mimic, control mimic. Data are expressed as the mean \pm SD from 3 independent experiments. (B) Decreased levels of vimentin and ZEB1 and increased level of E-cadherin were observed in A549 cells after transfection of miR-200b mimic by western blot analysis. Decreased level of ZEB1 and increased level of E-cadherin were also observed in A549 cells by miR-141 mimic induction on western blot analysis. Cont mimic, control mimic. (C and D) A549 cells and PC-1R cells treated with miR-200b or miR-141 mimic for $24 \mathrm{~h}$ were further incubated with various concentrations of nintedanib for $72 \mathrm{~h}$. Data are expressed as the mean \pm SD from 3 independent experiments.

A
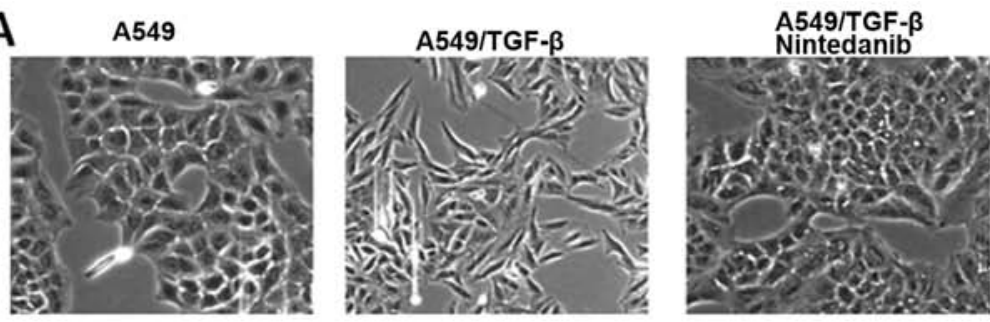

C
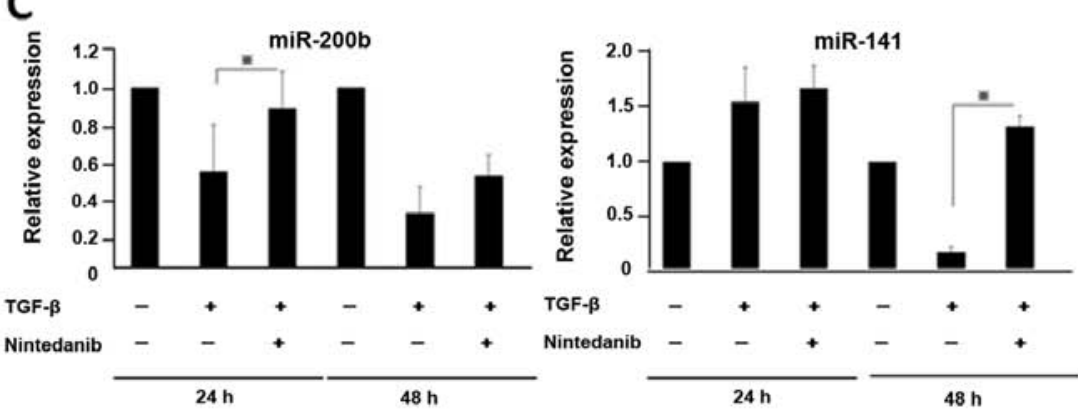
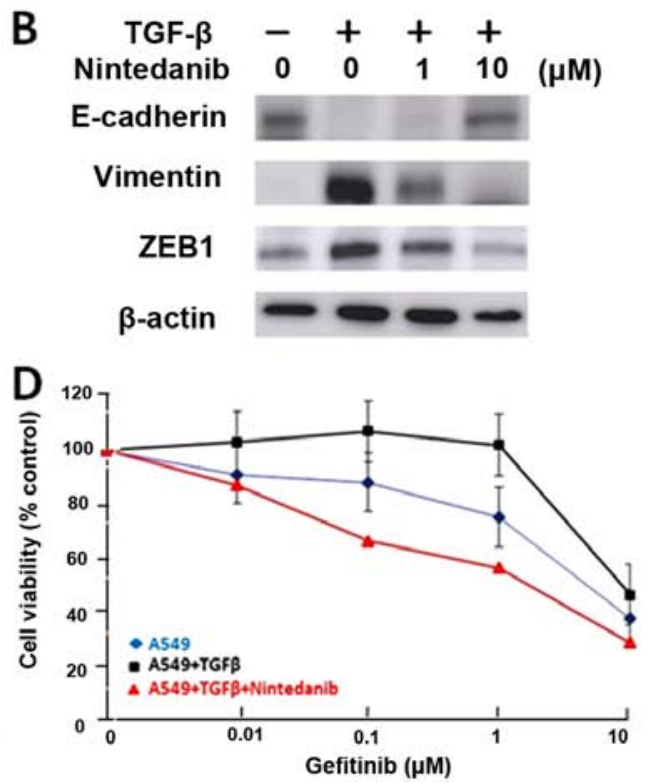

Figure 5. Nintedanib overcame resistance to gefitinib by activating the miR-200 family. (A) Morphologic change induced by TGF- $\beta 1$ exposure was recovered after treatment of A549 cells with $1 \mu \mathrm{M}$ nintedanib for $48 \mathrm{~h}$. (B) E-cadherin, vimentin and ZEB1 expression on western blot analysis. Decreased expression of E-cadherin and increased expression of vimentin and ZEB1 by TGF- $\beta 1$ exposure were recovered by $1 \mu \mathrm{M}$ nintedanib treatment in A549 cells for $48 \mathrm{~h}$. (C) TGF- $\beta 1$ exposure reduced miR-200b and miR-141 expression in A549 cells. After treatment with $1 \mu \mathrm{M}$ nintedanib, miR-200b and miR-141 expression recovered in A549 cells. Data are expressed as the mean \pm SD from 3 independent experiments. ${ }^{*} \mathrm{P}<0.05$. (D) TGF- $\beta 1$-exposed A549 cells that had been incubated with or without nintedanib for $24 \mathrm{~h}$ were further incubated with various concentrations of gefitinib for $72 \mathrm{~h}$. Each result is expressed as cell viability in the treated samples compared with the untreated sample (100\%) for gefitinib therapy. Data are mean \pm SD from 3 independent experiments.

response to gefitinib in A549 cells after treatment with nintedanib in combination with TGF- $\beta 1$. Nintedanib restored the resistance to gefitinib caused by TGF- $\beta 1$ in naturally resistant A549 cells (Fig. 5D). These results suggest that nintedanib 
combined with EGFR-TKI might be a novel therapeutic strategy for NSCLC cells with EMT phenotype.

\section{Discussion}

Although the effect of nintedanib monotherapy on NSCLC patients was limited, PFS was significantly improved in advanced NSCLC patients treated with nintedanib combined with docetaxel in the LUME-Lung-1 phase III study (12). This evidence suggests that nintedanib combined with anticancer agents might be a promising therapy in previously treated NSCLC patients. Therefore, identification of mechanisms of resistance to nintedanib is required for developing a therapeutic strategy in advanced NSCLC patients.

In the present study, low expression of miR-200b and miR-141, resulting in high level of ZEB1 and low level of E-cadherin, was associated with the resistance to nintedanib in NSCLC cells. The miR-200 family has been recognized as a main suppressor of EMT by targeting ZEB1 (23). EMT has been implicated in prevention of apoptosis and resistance to anticancer agents including EGFR-TKI in NSCLC cells. However, a method of overcoming EMT-associated resistance to anticancer drugs has not been established yet. In functional analysis in a recent report, nintedanib could reverse the EMT phenotype in lung cancer and pancreatic cancer cells (26). Our results showed that retention of the epithelial phenotype with high levels of miR-200 family ensured good sensitivity to nintedanib in NSCLC cells. In addition, induction of miR-200b and miR-141 showed reversal of EMT and increased sensitivity for nintedanib in both naturally resistant A549 and acquired resistant PC1-R cells. Expression of the miR-200 family and ZEB1 may be used as a predictive marker and therapeutic target for nintedanib therapy in NSCLC cells. Nintedanib therapy may be effective in NSCLC patients with the epithelial phenotype. A recent study showed that inhibition of miR-200 family targeting ZEB1 significantly enhanced the chemosensitivity to docetaxel in vitro and in vivo in lung adenocarcinoma cells with the EMT phenotype (27). This result may provide supporting evidence of the effectiveness of nintedanib combined with docetaxel in the LUME-Lung-1 study (12). The miR-200 family and its target ZEB1 may be common attractive targets of nintedanib and docetaxel therapies.

We also found that treatment with nintedanib caused reversal of TGF- $\beta 1$-induced EMT and resistance to gefitinib through upregulation of miR-200b and miR-141 in A549 lung cancer cells. These effects may be due to the multitargeted function of nintedanib, which inhibits FGFR as well as VEGFR and PDGFR. Reversal of EMT by nintedanib might be attributed to inhibition of fibroblast function. A recent report showed decreased levels of $\alpha$-SMA and S-100A4 in fibroblasts in pancreatic cancer xenografts after treatment with nintedanib (26). Alternatively, FGF pathway activation could provide an escape mechanism from anti-molecular targeted therapy in various cancers (28). FGFR promotes metastasis through EMT in breast tumors (29). FGFR1 inhibitor also restored EMT in head and neck squamous cell carcinoma (30). Taken together with our results, the reversal of EMT might be mainly regulated by FGFR inhibition of nintedanib. These findings demonstrated a novel role of nintedanib as a potential therapeutic strategy for resistance to EGFR-TKI associated with TGF- $\beta 1$-induced EMT in NSCLC cells. Overcoming EMT-associated resistance to EGFR-TKI would have extremely great benefit for EGFR-mutant NSCLC patients.

Nintedanib is also one of the promising drugs for IPF patients $(10,11)$. FDA approved nintedanib for the treatment of IPF. In addition, EMT is considered to contribute to IPF $(31,32)$. The mesenchymal markers collagen I, vimentin and $\alpha$-SMA were expressed in the bleomycin IPF model (31). A human IPF study has shown co-localization of epithelial and mesenchymal markers (32). It has been recognized that nintedanib has the potential to reduce disease progression, slowing the decline of lung function by blocking signaling pathways that are involved in fibrotic processes $(31,32)$. The miR-200 family also inhibited fibrogenic activity of pulmonary fibroblasts obtained from mice with experimental pulmonary fibrosis and from IPF patients (33). IPF is one of the most common complications in patients with lung cancer. Optimal treatments for lung cancer with IPF have not been established because of acute exacerbation of IPF caused by anticancer treatment in lung cancer patients with IPF (34). Our findings suggest that nintedanib can be used for the treatment of NSCLC patients with IPF as well as IPF patients.

In conclusion, the miR-200 family and ZEB1 could be used as predictive markers for sensitivity to nintedanib in NSCLC cells. Selection of patients for nintedanib therapy based on miR-200 family or ZEB1 expression may be useful in NSCLC patients. Nintedanib combined with EGFR-TKI might be a new therapeutic strategy for NSCLC patients with acquired resistance to EGFR-TKI by EMT. Further studies should be performed to clarify the effect of nintedanib on EMT and EGFR-TKI therapy in NSCLC.

\section{Acknowledgements}

We would like to thank Ms. Junko Murase and Mr. Hiroshi Terasaki of LSI Medience Corporation for analyzing genetic alterations.

\section{References}

1. Jemal A, Bray F, Center MM, Ferlay J, Ward E and Forman D: Global cancer statistics. CA Cancer J Clin 61: 69-90, 2011.

2. Lynch TJ, Bell DW, Sordella R, Gurubhagavatula S, Okimoto RA, Brannigan BW, Harris PL, Haserlat SM, Supko JG, Haluska FG, et al: Activating mutations in the epidermal growth factor receptor underlying responsiveness of non-small-cell lung cancer to gefitinib. N Engl J Med 350: 2129-2139, 2004.

3. Paez JG, Jänne PA, Lee JC, Tracy S, Greulich H, Gabriel S, Herman P, Kaye FJ, Lindeman N, Boggon TJ, et al: EGFR mutations in lung cancer: Correlation with clinical response to gefitinib therapy. Science 304: 1497-1500, 2004.

4. Soda M, Choi YL, Enomoto M, Takada S, Yamashita Y, Ishikawa S, Fujiwara S, Watanabe H, Kurashina K, Hatanaka H, et al: Identification of the transforming EML4-ALK fusion gene in non-small-cell lung cancer. Nature 448: 561-566, 2007.

5. Maemondo M, Inoue A, Kobayashi K, Sugawara S, Oizumi S, Isobe $\mathrm{H}$, Gemma A, Harada M, Yoshizawa H, Kinoshita I, et al; North-East Japan Study Group: Gefitinib or chemotherapy for non-small-cell lung cancer with mutated EGFR. N Engl J Med 362: 2380-2388, 2010 .

6. Zhou C, Wu YL, Chen G, Feng J, Liu XQ, Wang C, Zhang S, Wang J, Zhou S, Ren S, et al: Erlotinib versus chemotherapy as first-line treatment for patients with advanced EGFR mutationpositive non-small-cell lung cancer (OPTIMAL, CTONG-0802): A multicentre, open-label, randomised, phase 3 study. Lancet Oncol 12: 735-742, 2011. 
7. Wu YL, Zhou C, Hu CP, Feng J, Lu S, Huang Y, Li W, Hou M, Shi JH, Lee KY, et al: Afatinib versus cisplatin plus gemcitabine for first-line treatment of Asian patients with advanced non-smallcell lung cancer harbouring EGFR mutations (LUX-Lung 6): An open-label, randomised phase 3 trial. Lancet Oncol 15: 213-222, 2014.

8. Shaw AT, Kim DW, Nakagawa K, Seto T, Crinó L, Ahn MJ, De Pas T, Besse B, Solomon BJ, Blackhall F, et al: Crizotinib versus chemotherapy in advanced ALK-positive lung cancer. $\mathrm{N}$ Engl J Med 20 368: 2385-2394, 2013.

9. Hilberg F, Roth GJ, Krssak M, Kautschitsch S, Sommergruber W, Tontsch-Grunt U, Garin-Chesa P, Bader G, Zoephel A, Quant J, et al: BIBF 1120: triple angiokinase inhibitor with sustained receptor blockade and good antitumor efficacy. Cancer Res 15 68: 4774-4782, 2008.

10. Richeldi L, Costabel U, Selman M, Kim DS, Hansell DM, Nicholson AG, Brown KK, Flaherty KR, Noble PW, Raghu G, et al: Efficacy of a tyrosine kinase inhibitor in idiopathic pulmonary fibrosis. N Engl J Med 22 365: 1079-1087, 2011.

11. Richeldi L, du Bois RM, Raghu G, Azuma A, Brown KK, Costabel U, Cottin V, Flaherty KR, Hansell DM, Inoue Y, et al: Efficacy and safety of nintedanib in idiopathic pulmonary fibrosis. N Engl J Med 370: 2071-2082, 2014.

12. Reck M, Kaiser R, Mellemgaard A, Douillard JY, Orlov S, Krzakowski M, von Pawel J, Gottfried M, Bondarenko I, Liao M, et al; LUME-Lung 1 Study Group: Docetaxel plus nintedanib versus docetaxel plus placebo in patients with previously treated non-small-cell lung cancer (LUME-Lung 1): A phase 3, doubleblind, randomised controlled trial. Lancet Oncol 15: 143-155, 2014.

13. Johnson SM, Grosshans H, Shingara J, Byrom M, Jarvis R, Cheng A, Labourier E, Reinert KL, Brown D and Slack FJ: RAS is regulated by the let-7 microRNA family. Cell 120: 635-647, 2005.

14. Lu J, Getz G, Miska EA, Alvarez-Saavedra E, Lamb J, Peck D, Sweet-Cordero A, Ebert BL, Mak RH, Ferrando AA, et al: MicroRNA expression profiles classify human cancers. Nature 435: 834-838, 2005.

15. Volinia S, Calin GA, Liu CG, Ambs S, Cimmino A, Petrocca F, Visone R, Iorio M, Roldo C, Ferracin M, et al: A microRNA expression signature of human solid tumors defines cancer gene targets. Proc Natl Acad Sci USA 103: 2257-2261, 2006.

16. Yanaihara N, Caplen N, Bowman E, Seike M, Kumamoto K, Yi M, Stephens RM, Okamoto A, Yokota J, Tanaka T, et al: Unique microRNA molecular profiles in lung cancer diagnosis and prognosis. Cancer Cell 9: 189-198, 2006

17. Seike M, Goto A, Okano T, Bowman ED, Schetter AJ, Horikawa I, Mathe EA, Jen J, Yang P, Sugimura H, et al: MiR-21 is an EGFRregulated anti-apoptotic factor in lung cancer in never-smokers. Proc Natl Acad Sci USA 106: 12085-12090, 2009.

18. Kitamura K, Seike M, Okano T, Matsuda K, Miyanaga A, Mizutani H, Noro R, Minegishi Y, Kubota K and Gemma A: MiR-134/487b/655 cluster regulates TGF- $\beta$-induced epithelialmesenchymal transition and drug resistance to gefitinib by targeting MAGI2 in lung adenocarcinoma cells. Mol Cancer Ther 13: 444-453, 2014.

19. Seike M, Yanaihara N, Bowman ED, Zanetti KA, Budhu A, Kumamoto K, Mechanic LE, Matsumoto S, Yokota J, Shibata T, et al: Use of a cytokine gene expression signature in lung adenocarcinoma and the surrounding tissue as a prognostic classifier. $\mathrm{J}$ Natl Cancer Inst 99: 1257-1269, 2007.

20. Shimokawa T, Seike M, Soeno C, Uesaka H, Miyanaga A, Mizutani H, Kitamura K, Minegishi Y, Noro R, Okano T, et al: Enzastaurin has anti-tumour effects in lung cancers with overexpressed JAK pathway molecules. Br J Cancer 106: 867-875, 2012.
21. Bustin SA: Absolute quantification of mRNA using real-time reverse transcription polymerase chain reaction assays. J Mol Endocrinol 25: 169-193, 2000.

22. Sugano T, Seike M, Noro R, Soeno C, Chiba M, Zou F, Nakamichi S, Nishijima N, Matsumoto M, Miyanaga A, et al: Inhibition of ABCB1 overcomes cancer stem cell-like properties and acquired resistance to MET inhibition in non-small lung cancer. Mol Cancer Ther 14: 2433-2440, 2015.

23. Gregory PA, Bert AG, Paterson EL, Barry SC, Tsykin A, Farshid G, Vadas MA, Khew-Goodall Y and Goodall GJ: The miR-200 family and miR-205 regulate epithelial to mesenchymal transition by targeting ZEB1 and SIP1. Nat Cell Biol 10: 593-601, 2008.

24. Yauch RL, Januario T, Eberhard DA, Cavet G, Zhu W, Fu L, Pham TQ, Soriano R, Stinson J, Seshagiri S, et al: Epithelial versus mesenchymal phenotype determines in vitro sensitivity and predicts clinical activity of erlotinib in lung cancer patients. Clin Cancer Res 11: 8686-8698, 2005.

25. Suda K, Tomizawa K, Fujii M, Murakami H, Osada H, Maehara Y, Yatabe Y, Sekido Y and Mitsudomi T: Epithelial to mesenchymal transition in an epidermal growth factor receptormutant lung cancer cell line with acquired resistance to erlotinib. J Thorac Oncol 6: 1152-1161, 2011.

26. Kutluk Cenik B, Ostapoff KT, Gerber DE and Brekken RA: BIBF 1120 (nintedanib), a triple angiokinase inhibitor, induces hypoxia but not EMT and blocks progression of preclinical models of lung and pancreatic cancer. Mol Cancer Ther 12: 992-1001, 2013.

27. Ren J, Chen Y, Song H, Chen L and Wang R: Inhibition of ZEB1 reverses EMT and chemoresistance in docetaxel-resistant human lung adenocarcinoma cell line. J Cell Biochem 114: 1395-1403, 2013.

28. Casanovas O, Hicklin DJ, Bergers G and Hanahan D: Drug resistance by evasion of antiangiogenic targeting of VEGF signaling in late-stage pancreatic islet tumors. Cancer Cell 8: 299-309, 2005.

29. Qian X, Anzovino A, Kim S, Suyama K, Yao J, Hulit J, Agiostratidou G, Chandiramani N, McDaid HM, Nagi C, et al: $\mathrm{N}$-cadherin/FGFR promotes metastasis through epithelial-tomesenchymal transition and stem/progenitor cell-like properties. Oncogene 33: 3411-3421, 2014.

30. Nguyen PT, Tsunematsu T, Yanagisawa S, Kudo Y, Miyauchi M, Kamata N and Takata T: The FGFR1 inhibitor PD173074 induces mesenchymal-epithelial transition through the transcription factor AP-1. Br J Cancer 109: 2248-2258, 2013.

31. DeMaio L, Buckley ST, Krishnaveni MS, Flodby P, Dubourd M, Banfalvi A, Xing Y, Ehrhardt C, Minoo P, Zhou B, et al: Ligandindependent transforming growth factor- $\beta$ type I receptor signalling mediates type I collagen-induced epithelial-mesenchymal transition. J Pathol 226: 633-644, 2012

32. Kage $\mathrm{H}$ and Borok Z: EMT and interstitial lung disease: A mysterious relationship. Curr Opin Pulm Med 18: 517-523, 2012.

33. Yang S, Banerjee S, de Freitas A, Sanders YY, Ding Q, Matalon S, Thannickal VJ, Abraham E and Liu G: Participation of miR-200 in pulmonary fibrosis. Am J Pathol 180: 484-493, 2012.

34. Minegishi Y, Sudoh J, Kuribayasi H, Mizutani H, Seike M, Azuma A, Yoshimura A, Kudoh S and Gemma A: The safety and efficacy of weekly paclitaxel in combination with carboplatin for advanced non-small cell lung cancer with idiopathic interstitial pneumonias. Lung Cancer 71: 70-74, 2011. 